\title{
Erratum to: Cancer Health Professionals Need Funding, Time, Research Knowledge and Skills to be Involved in Health Services Research
}

\author{
Claire Johnson • Catalina Lizama • Megan Harrison • \\ Emma Bayly • Joshua Bowyer • Livia Haddow
}

Published online: 31 May 2014

(C) Springer Science+Business Media New York 2014

Erratum to: J Canc Educ

DOI 10.1007/s13187-014-0625-y

Authorship amendment: In the article "Cancer Health Professionals Need Funding, Time, Research Knowledge and Skills to be Involved in Health Services Research" which was published online in the Journal of Cancer Education on 9 February 2014, the last author was erroneously omitted from the author list. It should have shown the final author to be Livia Haddow, from the WA Cancer and Palliative Care Research and Evaluation Unit (CaPCREU), School of Surgery M507, The University of Western Australia, 35 Stirling Hwy, Crawley, WA, 6009, Australia.

The online version of the original article can be found at http://dx.doi.org/ 10.1007/s13187-014-0625-y.

C. Johnson $(\triangle) \cdot$ C. Lizama • M. Harrison • E. Bayly · J. Bowyer

L. Haddow

WA Cancer and Palliative Care Research and Evaluation Unit

(CaPCREU), School of Surgery M507, The University of Western

Australia, 35 Stirling Hwy, Crawley, WA 6009, Australia

e-mail: claire.johnson@uwa.edu.au 